Revue d'histoire de l'Amérique française

DEVUE D.HISTOIRE DE L'AMÉRIQUE FRANÇAISE

\title{
Erratum
}

\section{McCALLUM, John, Unequal Beginnings: Agriculture and Economic Development in Quebec and Ontario until 1870. Toronto, University of Toronto Press, 1980.148 p. \$5.95.}

Volume 35, numéro 3, décembre 1981

URI : https://id.erudit.org/iderudit/018565ar

DOI : https://doi.org/10.7202/018565ar

Aller au sommaire du numéro

\section{Éditeur(s)}

Institut d'histoire de l'Amérique française

\section{ISSN}

0035-2357 (imprimé)

1492-1383 (numérique)

Découvrir la revue

Citer ce document

(1981). Erratum / McCALLUM, John, Unequal Beginnings: Agriculture and Economic Development in Quebec and Ontario until 1870. Toronto, University of Toronto Press, 1980. 148 p. \$5.95. Revue d'histoire de l'Amérique française, 35(3), 407-407. https://doi.org/10.7202/018565ar d'utilisation que vous pouvez consulter en ligne. 


\section{COMPTES RENDUS}

McCALLUM, John, Unequal Beginnings: Agriculture and Economic Development in Quebec and Ontario until 1870. Toronto, University of Toronto Press, 1980.148 p. $\$ 5.95$

Note rectificative. Une erreur s'est glissée dans le compte rendu de cet ouvrage, paru dans le dernier numéro de la $R H A F$. À la page 284 , il aurait fallu lire monopsonistique au lieu de monopolistique. Vu que cette erreur en est une de fond, nous tenons à la rectifier, et nous nous excusons auprès de l'auteur du compte rendu, Robert Armstrong.

ALLARD, Michel et al. Histoire nationale du Québec, de sa découverte à aujourd'hui. Montréal, Guérin, 1980. xvii-335 p., ill., cartes, graph., tabl., index. $\$ 11.95$

Il faut du courage pour publier, en 1980, un manuel scolaire d'histoire nationale alors que l'on sait, depuis deux ans, que l'ancien programme est condamné et que le nouveau, dont les brouillons commencent à peine à circuler, ne sera of ficiellement dévoilé qu'au cours de 1981 . Les auteurs de l'Histoire nationale du Québec ont eu ce courage. Il convient de les en féliciter.

Réalisé par un professeur d'université et cinq professeurs du secondaire, le manuel Histoire nationale du Québec est destiné à «l'étudiant qui aborde l'étude de l'histoire de son pays pour la première fois» (Avant-propos, p. xvii). Il «s'adresse particulièrement aux étudiants [élèves?] du deuxième cycle du secondaire» (Id.).

C'est un manuel qui semble fermement ancré dans la tradition de l'histoire narrative. Il garde les divisions chronologiques traditionnelles, et accorde à chacune sensiblement le même nombre de pages. Il conserve le récit événementiel à base politique et constitutionnelle, marqué à l'occasion de «grands hommes» et de hauts faits. La liste des titres de la troisième partie de l'ouvrage, qui va de 1867 à nos jours, en est une bonne illustration: Le Québec de 1867; Les Conservateurs se succèdent; Honoré Mercier; L'époque libérale; Les politiques de Taschereau; Maurice Le Noblet Duplessis; L'Union nationale; La révolution tranquille; Le retour de l'Union nationale; Nouvelle équipe libérale; Le Parti québécois. Le tout se termine sur un Appendice qui rappelle la chronologie de la période, fait les listes des premiers ministres du Québec, du Canada, des lieutenants-gouverneurs, et des résultats détaillés de toutes les élections générales... On devine que ce manuel est plus une histoire de la gestion politique de la nation qu'une histoire des Québécois.

On devine aussi qu'il s'agit moins de comprendre que d'apprendre, et moins encore d'apprendre à comprendre. L'important est de retenir, et 